Review

\title{
Organic acid toxicity, tolerance, and production in Escherichia coli biorefining applications
} Tanya Warnecke and Ryan T Gill*

\author{
Address: Department of Chemical and Biological Engineering, UCB424/ECCH120, University of Colorado, Boulder, CO 80309, USA \\ Email: Tanya Warnecke - tanya.warnecke@colorado.edu; Ryan T Gill* - rtg@colorado.edu \\ * Corresponding author
}

Published: 25 August 2005

Microbial Cell Factories 2005, 4:25 doi:10.I 186/1475-2859-4-25
Received: 08 July 2005

Accepted: 25 August 2005

This article is available from: http://www.microbialcellfactories.com/content/4///25

(c) 2005 Warnecke and Gill; licensee BioMed Central Ltd.

This is an Open Access article distributed under the terms of the Creative Commons Attribution License (http://creativecommons.org/licenses/by/2.0), which permits unrestricted use, distribution, and reproduction in any medium, provided the original work is properly cited.

\begin{abstract}
Organic acids are valuable platform chemicals for future biorefining applications. Such applications involve the conversion of low-cost renewable resources to platform sugars, which are then converted to platform chemicals by fermentation and further derivatized to large-volume chemicals through conventional catalytic routes. Organic acids are toxic to many of the microorganisms, such as Escherichia coli, proposed to serve as biorefining platform hosts at concentrations well below what is required for economical production. The toxicity is two-fold including not only $\mathrm{pH}$ based growth inhibition but also anion-specific effects on metabolism that also affect growth. $E$. coli maintain viability at very low $\mathrm{pH}$ through several different tolerance mechanisms including but not limited to the use of decarboxylation reactions that consume protons, ion transporters that remove protons, increased expression of known stress genes, and changing membrane composition. The focus of this mini-review is on organic acid toxicity and associated tolerance mechanisms as well as several examples of successful organic acid production processes for $E$. coli.
\end{abstract}

\section{Review \\ Biorefining Platforms}

Biorefining promises the development of efficient processes for the conversion of renewable sources of carbon and energy into large volume commodity chemicals. It has been estimated that such bioprocesses already account for $5 \%$ of the 1.2 trillion dollar US chemical market [1], with some projecting future values of up to $50 \%$ of the total US chemical market generated through biological means. While the attractiveness of such bioprocesses has been recognized for some time [2,3], recent advances in biological engineering and associated sciences [4-15], several biorefining success stories [16-18], and instability in the price and future availability of oil [19], have collectively reinvigorated interest in the large scale production of chemicals through biological routes. Nevertheless, many challenges still remain for the economical bio-production of commodity chemicals. Such challenges encompass the need to not only inexpensively convert biomass into usable sources of carbon and energy but also to engineer microbes to produce relevant chemicals at high titers and productivities while minimizing the generation of byproducts that might foul downstream processes $[1,20,21]$. One model for addressing the latter of such challenges involves the generation of platform organisms that can be easily engineered and re-engineered to produce a variety of building block chemicals that are amenable to conversions to higher value products via traditional catalytic routes (see Figure 1). Although chemical pretreatment of raw materials impairs viability of platform organisms, this review will focus on product toxicity issues associated with the production of organic acids in 


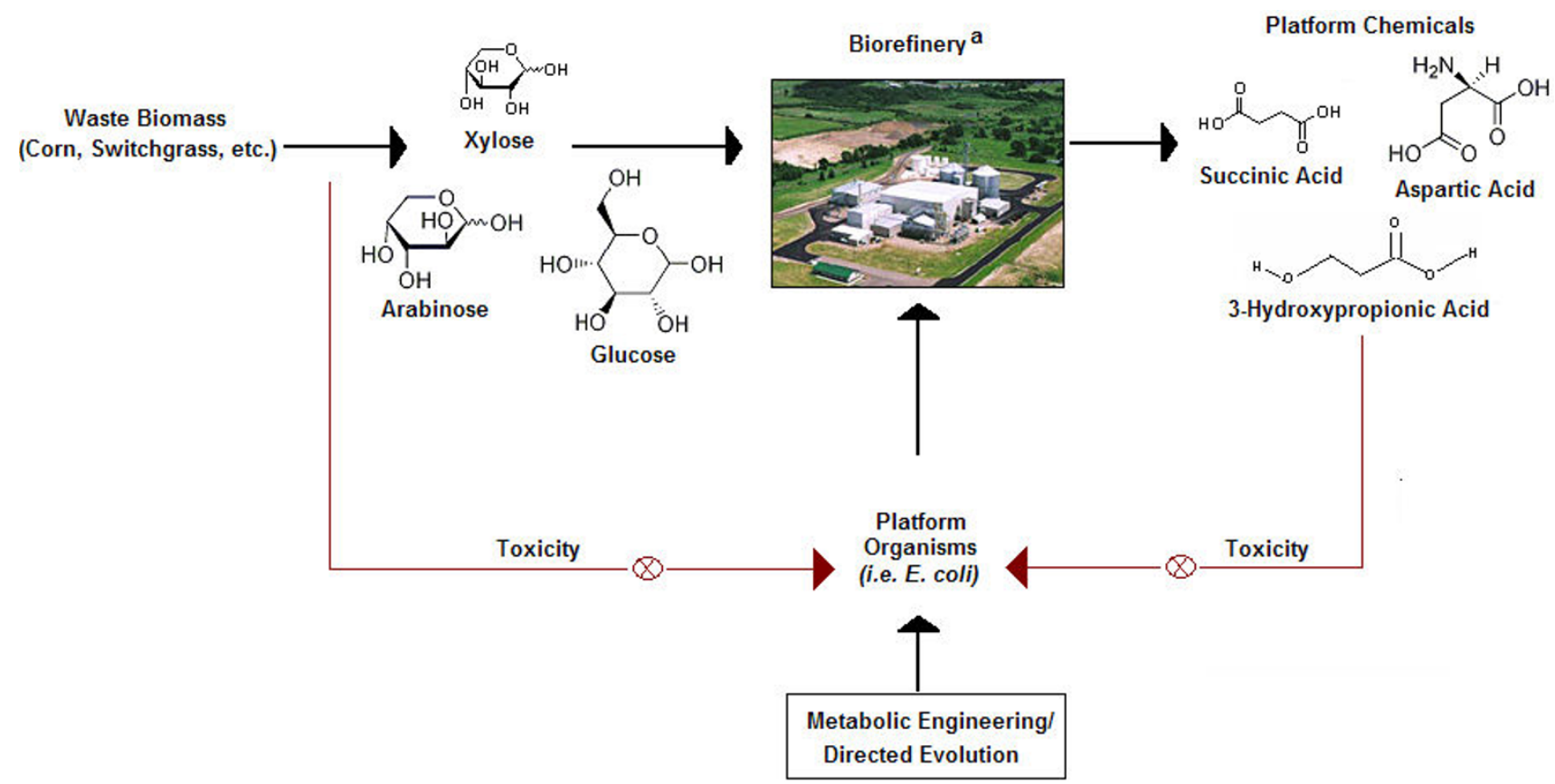

a. Golden Valley, MN www.biorefining.com

\section{Figure I}

Conceptual model of toxicity in biorefining applications. Sugars are extracted from waste biomass for use as feedstock for platform organisms in a biorefinery. Metabolically engineered microorganisms convert sugars into valuable platform chemicals that are then further derivatized to large-volume chemicals. Product and feedstock toxicity are observed, thus limiting productivity of biorefining applications.

E. coli (for further information on sugar extraction from raw materials see Zaldavar, et al. [22] and Knauf, et al. [23]).

The US Department of Energy (USDOE) recently released a prioritized list of building block chemicals for future biorefining endeavors. Priority was assigned based on the projected value of the platform chemical and potential derivatives as well as what technological developments were required for the production of the chemical and associated derivatives [21]. The report emphasized the importance of organic acids to the future of biorefining efforts (eight of the top twelve chemicals were organic acids, see Table 1 in additional file 1). The USDOE is not the first to recognize the importance of organic acids. In fact, there is a rich literature describing microbial production of organic acids $[17,20,24,25]$, including several successful commercial bioprocesses [26-28]. Product toxicity is one of the primary challenges in the development of organic acid bioprocesses based on the use of platform host organisms, such as E. coli. In particular, while E. coli is known to survive very high concentrations of acids $(\mathrm{pH}$ $=2$ ) when passing through the mammalian stomach, $E$. coli are surprisingly acid sensitive in exponential phase when cultured planktonically $[29,30]$. Moreover, undisso- ciated organic acids, which pass freely through the outer and plasma membranes of E. coli $[31,32]$, dissociate upon entry into the slightly alkaline cytoplasm releasing protons that lower internal $\mathrm{pH}\left(\mathrm{pH}_{\mathrm{i}}\right)$ and anions that specifically inhibit different aspects of metabolism resulting in impaired growth [33-35]. Titers and productivities of 50$100 \mathrm{~g} / \mathrm{L}$ and $2-3 \mathrm{~g} / \mathrm{L} \cdot \mathrm{hr}$ are expected for the economical manufacturing of most building block acids by fermentation. The pKa values range from 3-5 for these organic acids, which would result in a pH reduction to around 2.0 for titers of $50 \mathrm{~g} / \mathrm{L}$. This highlights a key challenge in the metabolic engineering of organic acid production hosts. That is, high titers result in the addition of protons to the culture, which either result in a decreased $\mathrm{pH}$ or the addition of large volumes of base titrant. At low $\mathrm{pH}$, organic acids are undissociated, thus they pass freely through the membrane and inhibit growth. At high $\mathrm{pH}$, the process is less efficient due to base requirements and because export of the organic acid cannot proceed by free diffusion alone (for a more detailed discussion of organic acid export issues see Van Maris et al. [36]). What is desired, therefore, is a platform organism that not only produces high levels of organic acid chemicals but also is tolerant to any associated toxicity. 
Many microbes are capable of producing platform chemicals by aerobic and anaerobic fermentation processes [22]. L-lactic acid has traditionally been produced by lactic acid bacteria. Although many lactic acid bacteria strains have been studied extensively [37], the ability to produce optically pure L-lactic acid is hampered by the presence of both $\mathrm{L}$ and $\mathrm{D}$ lactate dehydrogenase genes [38]. Pure Llactic acid must therefore be produced via another pathway, as the racemic acid product is not useful for downstream conversion into polylactic acid. A number of other microorganisms have been used for industrial fermentation of several of the building block organic acids identified in Table 1. Large scale production of amino acids has been accomplished in Corynebacteriumglutamicum [39], succinic acid has been produced by Actinobacillus succinogenes [40], and itaconic acid production has been carried out with Aspergillus terrus [41]. While successful, the future application of these organisms as platform hosts is limited when compared with E. coli. E. coli is advantageous as a platform host because it is the most well characterized model organism, it has been used in recombinant processes for over 20 years, there are a wide variety of good genetic tools, and it is sensitive to many antibiotics used in genetic engineering efforts [42]. Moreover, the completion of the E. coli genome sequence has already enabled many functional genomics studies and proven useful in metabolic engineering efforts [43]. Finally, E. coli grows quickly in minimal media and maintains the ability to metabolize both 5 and 6 carbon sugars, which is a specific advantage over the use of industrially relevant yeast strains [22]. This mini-review will describe the basic mechanisms underlying organic acid toxicity and associated tolerance pathways in E. coli followed by a short discussion of several metabolic engineering strategies employed for the production of organic acids in E. coli.

\section{Organic Acid Toxicity in E. coli}

One of the primary factors contributing to the toxicity of organic acids is their ability to diffuse across E. coli cellular membranes when undissociated as opposed to the restricted passage of dissociated protons and anions (see Figure 2) [31,32]. Diffusion of dissociated acids is limited to secondary transport, which is known to involve $\mathrm{H}+$ / monocarboxylic acid symporters. However, the detailed mechanism and specificities of the transporters remain unknown [31]. E. coli maintain a cytoplasmic $\mathrm{pH}\left(\mathrm{pH}_{\mathrm{i}}=\right.$ 7.5) that is most often higher than that of the external media and typically well above the pKa of organic acids $[44,45]$. As a result, organic acids exist in the dissociated form within the cytoplasm. Thus, diffusing organic acids entering into the cytoplasm will dissociate and disrupt the pHi and anion pool of the cytoplasm. The resulting increase in internal acidity can affect the integrity of purine bases [46] and result in denaturing of essential enzymes inside the cell [35], both of which negatively affect cell viability.

Organic acid anions affect cell growth in a variety of manners. Increased anion concentration has been shown to lead to an increased transport of potassium ions into the cell, which increases turgor pressure $[47,48]$. To maintain a constant turgor pressure and cell volume, glutamate is transported out of the cell [48]. This transport activity concomitantly disrupts the osmolarity of the cytoplasm, which in turn lowers the cell's growth potential and viability. In addition to this general anion effect, there are also effects specific to each organic acid. It has been proposed that enzymes involved in protein synthesis are sensitive to a combination of two unrelated mechanisms, including the acidification of $\mathrm{pHi}$ and the formation of an anionic pool [35]. Although this finding implies that the organic inhibition due to the anion pool could be acid specific, the details describing this dual inhibition mechanism remain unclear. Kirkpatrick et al. reported proteins exhibiting increased expression in response to extracellular acetate [33]. Among these are the OppA transporter, RpoS regulon, several amino acid uptake proteins, DNA binding proteins, and extreme-acid preiplasmic chaperones. Interestingly, when formate was introduced in place of acetate the expression of the previously mentioned proteins was repressed, indicating that the response was anion specific. This finding introduces new challenges in addressing organic acid tolerance. Specifically, it highlights the need to engineer both $\mathrm{pH}$ and as well as specific anion tolerance into host organisms.

Finally, production of organic acids might include intermediates that are themselves toxic. For example, 3hydroxypropionic acid (3HP) is closely related to the antimicrobial compound Reuterin. Reuterin describes the hydroxypropionaldehyde (HPA) system including HPA, HPA dimer, and HPA hydrate. Reuterin is inhibitory to several bacteria, including E. coli, at concentrations as low as $0.03-0.05 \mathrm{~g} / \mathrm{L}[49-51]$. It is thought that the toxicity could be the result of inhibition of DNA synthesis [52]. It has been postulated that the reactivity of the aldehyde group of HPA causes DNA damage similarly to formaldehyde, which is the aldehyde analog of formic acid [49]. Intermediate toxicity can be managed either by optimization of the production pathway in the host or by engineering tolerance to the intermediate itself.

\section{Organic Acid Tolerance in E. coli}

E. coli has a remarkable ability to remain viable under a broad range of $\mathrm{pH}$ conditions. This ability is essential for its survival in the mammalian digestive system where $\mathrm{pH}$ can vary between $\mathrm{pH}=2-8$. Several different acid tolerance mechanisms have been identified in $E$. coli. While each mechanism is capable of providing some degree of 


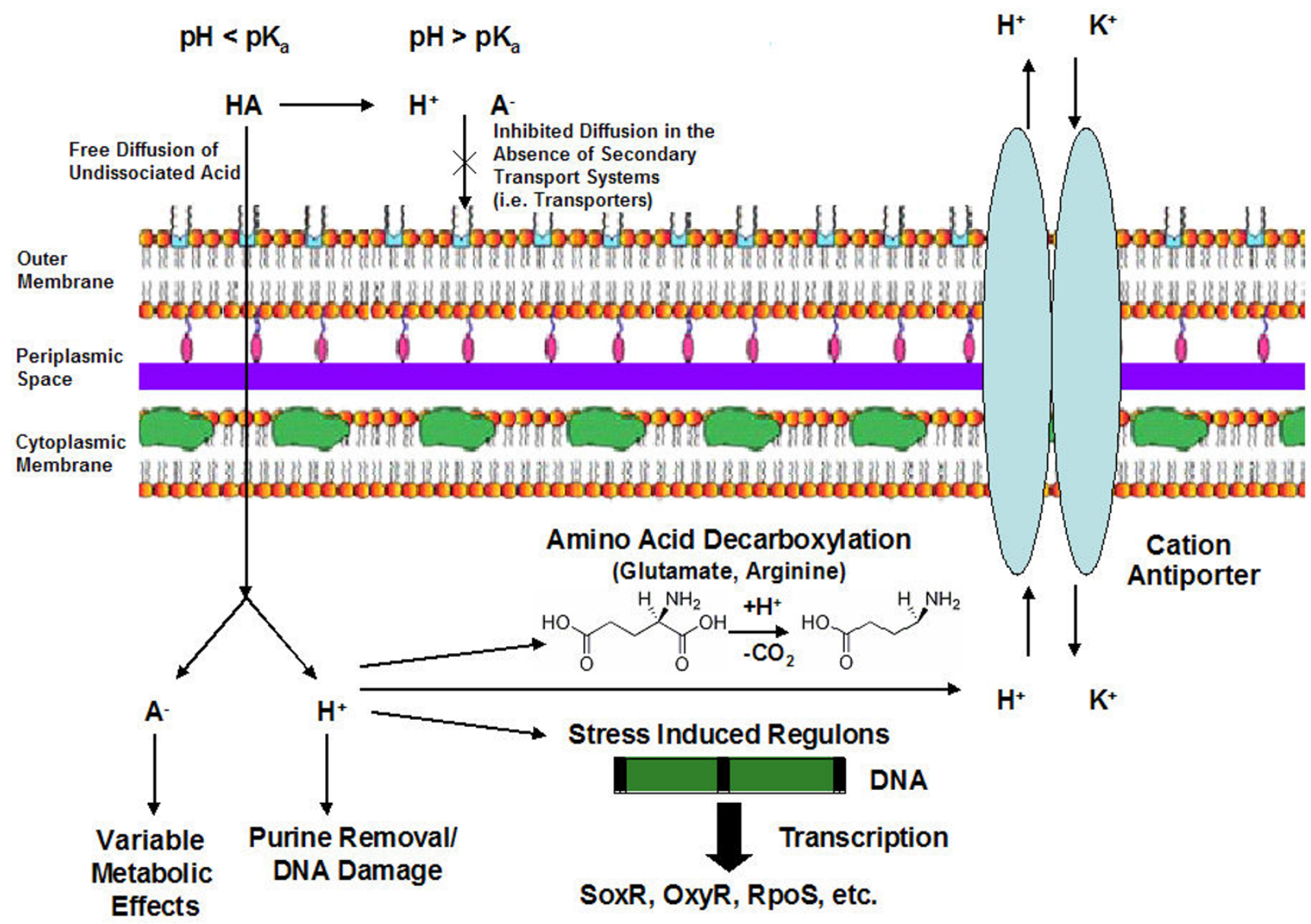

Figure 2

An overview of organic acid toxicity and tolerance mechanisms in E. coli. Diffusion of undissociated acid molecules can occur freely in acidic medium but is limited to transport systems at neutral or basic $\mathrm{pH}$. The toxic effects associated with organic acids are the result of both anion specific affects on metabolism as well as increased internal proton concentrations. Affects on internal $\mathrm{pH}$ are mitigated by transport of protons out of the membrane, consumption of protons by decarboxylation reactions, and, more generally, induction of stress regulons. Anion specific tolerance mechanisms are not well characterized.

tolerance, they are regulated differently and confer varying levels of tolerance.

Although most acid tolerance systems are activated in stationary phase, acid tolerance as low as $\mathrm{pH}=3$ has been observed in exponential phase E. coli grown under aerobic conditions, which is advantageous from a productivity standpoint [30]. Although the underlying tolerance mechanism is not known, such tolerance can be reliably activated by adapting cells at sublethal $\mathrm{pH}$ values between 4.3 and 5.8 [53]. E. coli that exhibit growth phase tolerance remain viable at $\mathrm{pH}$ values on the same order as stationary phase tolerance, however the percent survival is significantly lower. Lin et al. reported $1 \%$ survival of the original culture following acid adaption at $\mathrm{pH} 4.3$ followed by acid challenge at pH 3.3 compared to $0.0001 \%$ survival for unadapted cultures. This is compared to stationaryphase cultures, which exhibited up to $50 \%$ survival.

Three stationary phase acid resistance systems have been studied in the most detail $[29,30]$. These systems confer the highest levels of tolerance and are believed to be responsible for stationary phase E. coli survival when passing through the mammalian stomach. Acid resistance system 1 (AR1) is activated in slightly acidic media ( $\mathrm{pH} 5.5$ ) in the absence of extracellular glucose or amino acids. E. coli grown aerobically under these conditions retain viability under acid challenges as low as $\mathrm{pH}=2.5$ [54]. This 
system is also referred to as the oxidative or glucoserepressed system, since the expression of this system is thought to be regulated either directly or indirectly by RpoS and cyclicAMP receptor protein (CRP) [55,56]. Acid resistance system 2 (AR2) is activated in E. coli grown in aerobic conditions in acidic complex media. This system requires the presence of extracellular glucose and glutamate and is dependent upon genes encoding glutamate decarboxylase (gadAB) and a glutamate:GABA antiporter $(g a b C)$ [30]. Under such conditions, E. coli have been demonstrated to exhibit acidic resistance up to a $\mathrm{pH}$ of 2 . The mechanism involves the expenditure of excess cytoplasmic protons during amino acid decarboxylation reactions (see Figure 2), thus raising the internal pH [54,55]. Acid resistance system 3 (AR3) parallels the mechanisms of AR2 with several slight deviations [30,54,55]. AR3 is activated under anaerobic conditions, in complex media with added glucose. It also involves amino acid decarboxylation reactions to lower the internal $\mathrm{pH}$, but requires extracellular arginine in place of glutamate. AR3 also requires increased expression of arginine decarboxylase and an arginine: agmatine antiporter for increased acid tolerance.

Finally, several general acid tolerance mechanisms that regulate the physical properties of the membrane or the effectiveness of ion transport have been identified. These active responses, or those that occur as a result of the cell's ability to sense $\mathrm{pH}$ changes, are independent of growth and are induced by $\mathrm{pH}$ shifts as small as $0.2 \mathrm{pH}$ units [57]. The first response is the ability of the microorganism to adjust membrane properties, such as lipid content, thus effectively changing the proton permeability [57]. Another cellular response to acid shock is the induction of genes responsible for repairing and preventing lethal cellular damage. Specifically, increased expression of the oxy $R$ and soxR regulatory genes has been observed by transcriptional profiling of acid tolerant phenotypes [45,58]. These systems regulate the removal of damaging oxidizing agents, thus preventing further DNA damage under acidic stress [46]. Finally, acid tolerance can be achieved by adjusting the ionic transporter efficiency, effectively regulating the anion and cation balance as a means of maintaining a constant internal $\mathrm{pH}$ [47].

\section{Organic Acid Production in E. coli}

Metabolic and genetic engineering, directed evolution, and classic strain selection have all been employed in the development of E. coli strains that produce building block organic acids, including lactic-acid, succinic acid, and 3HP $[17,25,59,60]$. Improved titers have been achieved due to optimization of fermentation conditions and relavant pathways utilized. However, titer limitations exist when fermentation is carried out in unbuffered media, which allows the $\mathrm{pH}$ to acidify due to increased acid concentra- tion. Alternatively large amounts of base titrant are required to raise the $\mathrm{pH}$ of the media during the organic acid production leaving the final acid molecule in the undissociated form. Following production under these conditions, large volumes of acid must be added to recover the acid in the protonated form. Metabolic and genetic engineering of acid tolerance into production strains, making fermentation at a $\mathrm{pH}$ less than the $\mathrm{pKa}$ of the acid produced possible, would circumvent the need for the additional consumption of acid and base titrants, and thus lower the overall production cost. Similarly, engineering strain fitness to increase productivity at a decreased $\mathrm{pH}$ would improve productivity and reduce base consumption.

Lactic acid production is one of the most successful examples to date of the engineering of large volume chemical production in E. coli. E. coli was selected as a favorable host strain due to its ability to consume both pentose and hexose sugars and to generate optically pure L-lactic acid, which is the desired product for downstream polylactic acid (PLA) production $[61,62]$. An effective lactic acid producing strain of $E$. coli was created by induced expression of the L-specific lactic acid dehydrogenase (LDH) gene from Streptococcus bovis. High titers (50-75 g/L) were observed under controlled $\mathrm{pH}(\mathrm{pH}=7)$ and anaerobic conditions. Titers were drastically decreased (10-20 g/L) as the $\mathrm{pH}$ was allowed to drop with increasing acid production [59]. However, allowing the $\mathrm{pH}$ to fall below the pKa of lactic acid also resulted in decreased concentration of the acid in the undissociated form, which facilitated the subsequent isolation of the protonated acid. Interestingly, the choice of host strain made a significant difference in lactic acid production [59]. Those constructed from an E. coli B strain showed a titer of almost twice that produced from K12 derivatives. The increased production was attributed primarily to differences in the native growth characteristics rather than increased acid tolerance.

Economically competitive titers of succinic acid have also been achieved in $E$. coli. Strains were engineered to limit flux to other anaerobic byproducts normally formed during fermentation [60]. Specifically, succinic acid production was optimized by redirecting the metabolic flux at the pyruvate node away from lactate and formate through inactivation of the pyruvate-formatelyase and lactate dehydrogenase $[60,63]$. The maximum yield in succinic acid production was approximately $50 \mathrm{~g} / \mathrm{L}$ in $\mathrm{pH}$ controlled cultures. However, similar to lactic acid studies, succinic acid production was significantly repressed when $\mathrm{pH}$ was not kept at neutral levels.

A final example of metabolic engineering organic acid production in E. coli was reported by Cargill in 2001 [17]. Suthers and Cameron engineered a 2-step glycerol to $3 \mathrm{HP}$ 
pathway in E. coli. Glycerol was first converted to 3HPA via a glycerol dehydratase enzyme ( $\mathrm{dhaB}$ - isolated from Klebsiella pneumoniae). 3HPA was then converted to 3HP via an aldehyde dehydrogenase (ald). This first pathway was not ideal for several reasons including a very low reported titer $(0.2 \mathrm{~g} / \mathrm{L})$, the use of the more expensive glycerol as opposed to glucose, and the generation of the highly toxic 3-HPA (reuterin) compound. Selifinova et al. later proposed five additional pathways for the production of 3-HP directly from glucose in E. coli [36]. Results for each of such pathways have yet to be reported. One issue that has yet to be addressed is how to fulfill the desire to produce 3-HP at a $\mathrm{pH}$ below the $\mathrm{pKa}=4.51$ of 3 $\mathrm{HP}$, which would lessen the dependency on large volumes of base titrant to retain neutral $\mathrm{pH}$ at high titers.

Metabolic engineering of E. coli organic acid tolerance represents an important future opportunity. As discussed above, E. coli possess several systems for surviving $\mathrm{pH}$ as low as 2.0, which is much lower than what is required for an economical biorefining process. Since induction of these systems is well characterized and the relevant genes are known in many cases, future efforts might be better focused on the development of multi-stage fermentations that allow for generation of biomass prior to induction of acid tolerance and, ultimately, acid production. Future genetic engineering efforts might focus on engineering tolerance against the less well characterized metabolic effects associated with increased organic acid anion concentrations. For example, the addition of acetate, benzoate, and propionate to culture media at a concentration of $8 \mathrm{mM}$ has been observed to inhibit growth of $E$. coli up to $50 \%$ [35]. The acetate inhibition is thought to be caused by limited methionine pools combined with increasing concentrations of homocysteine, a toxic intermediate, due to inactivation of a key enzyme in the methionine synthesis pathway, which can be countered by the addition of methionine to the media. This finding established that growth inhibition is the result of both of lowered $\mathrm{pH}$ and specific anionic effects, which decreases the activity of key enzymes. Thus, engineering tolerance to specific organic acid anion effects by increased expression of inhibited enzymes could aid in increasing overall process productivity.

\section{Conclusion}

Organic acids are a valuable sector of the industrial chemical market, which have already been successfully produced through microbial fermentation. However, product titers have been variable, ranging from less than $1 \mathrm{~g} / \mathrm{L}$ to concentrations cost competitive with current petrochemical production processes. These fermentation processes have been limited in E. coli due to product and intermediate toxicity. Toxicity is directly measured by growth inhibition, which specifically decreases productivity. This review highlighted what is known about organic-acid toxicity and tolerance mechanisms in E. coli. Specifically, E. coli are growth inhibited by the increase in both proton and associated anion concentrations that are characteristic of organic-acid production processes. While several acidtolerance mechanisms have been characterized in E. coli, anion specific mechanisms require additional study. Thus, future metabolic engineering efforts that seek to improve understanding of these issues within the context of organic-acid biorefining applications should prove useful.

\section{Additional material}

\section{Additional File 1}

Table 1: Organic acids for platform biorefining applications. ( ${ }^{*}$ see references $[64,65])$

Click here for file

[http://www.biomedcentral.com/content/supplementary/1475-

2859-4-25-S1.doc]

\section{References}

I. Bachmann R, Riese J: From promise to profit. Industrial Biotechnology 2005, I(I):9-I5.

2. Leeper SA, Ward TE, Andrews GF: Production of Organic Chemicals via Bioconversion: A Review for Potential. US DOE's Idaho Operations Office; I99I.

3. Herrera S: Industrial biotechnology - a chance at redemption. Nature Biotechnology 2004, 22(6):67I-675.

4. Crameri A, Raillard S, Bermudez E, Stemmer WPC: DNA shuffling of a family of genes from diverse species accelerates directed evolution. Nature 1994, 370:389-390.

5. Patnaik R, Louie S, Gavrilovic V, Perry K, Stemmer WPC, Ryan CM, del Cardayré S: Genome shuffling of Lactobacillus for improved acid tolerance. Nature Biotechnology 2002, 20(7):707-7I2.

6. Canada KA, Iwashita S, Shim H, Wood TK: Directed evolution of toluene ortho-monooxygenase for enhanced I-naphthol synthesis and chlorinated ethene degradation. Journal of Bacteriology 2002, I 84(2):344-349.

7. Farmer WR, Liao JC: Improving lycopene production in Escherichia coli by engineering metabolic control. Nature Biotechnology 2000, I 8(5):533-537.

8. Fodor SPA, Read JL, Pirrung MC, Stryer L, Lu AT, Solas D: LightDirected, Spatially Addressable Parallel Chemical Synthesis. Science I99I, 25 I (4995):767-773.

9. Gill RT, Wildt S, Yang YT, Ziesman S, Stephanopoulos G: Genomewide screening for trait conferring genes using DNA microarrays. Proceedings Of The National Academy Of Sciences Of The United States Of America 2002, 99( I 0):7033-7038.

I0. Martin VJJ, Pitera DJ, Withers ST, Newman JD, Keasling JD: Engineering a mevalonate pathway in Escherichia coli for production of terpenoids. Nature Biotechnology 2003, 2 I (7):796-802.

II. Ohnishi J, Mitsuhashi S, Hayashi M, Ando S, Yokoi H, Ochiai K, Ikeda $M$ : A novel methodology employing Corynebacterium glutamicum genome information to generate a new Llysine-producing mutant. Applied Microbiology And Biotechnology 2002, 58(2):217-223.

12. Schmidt-Dannert C, Umeno D, Arnold FH: Molecular breeding of carotenoid biosynthetic pathways. Nature Biotechnology 2000, I 8(7):750-753.

13. Bailey JE: Towards a science of metabolic engineering. Science |991, 252:1668-1675.

14. Bailey JE, Sburlati A, Hatzimanikatis V, Lee K, Renner WA, Tsai PS: Inverse metabolic engineering: $A$ strategy for directed 
genetic engineering of useful phenotypes. Biotechnology And Bioengineering 2002, 79(5):568-579.

15. Stephanopoulos G, Vallino J]: Network Rigidity And Metabolic Engineering In Metabolite Overproduction. Science |99|, 252(50I3): 1675-168I.

16. Higley DP, Sun Y: Acid-dyeable polymer compositions. US patent 938760. 2004.

17. Suthers PF, Cameron DC: Production of 3-Hydroxypropionic acid in recombinant organisms. PCT WO $0 \mathrm{I}-16346.200 \mathrm{I}$

18. Gatenby AA, Haynie SL, Nagarajan: Method for the production of I,3-propanediol by recombinant organisms. WO 9821339 . 1998.

19. Deffeyes KS: Hubbert's Peak: The Impending World Oil Shortage. Princeton, NJ , Princeton University Press; 2001.

20. Chotani G, Dodge T, Hsu A, Kumar M, LaDuca R, Trimbur D, Weyler $W$, Sanford K: The commercial production of chemicals using pathway engineering. Biochimica Et Biophysica Acta-Protein Structure And Molecular Enzymology 2000, I543(2):434-455.

21. Werpy T, Petersen G: Top Value Added Chemicals from Biomass. In Volume I: Results of Screening for Potential Candidates from Sugars and Synthetic Gas Oak Ridge, TN , U.S. Department of Energy; 2004.

22. Zaldivar J, Nielsen J, Olsson L: Fuel ethanol production from lignocellulose: a challenge for metabolic engineering and process integration. Applied Microbiology And Biotechnology 200I, 56(I-2): 17-34.

23. Knauf M, Moniruzzaman M: Lignocellulosic biomass processing: A perspective. International Sugar Journal 2004, 106(1263): 147-150.

24. Trends in Life Sciences: US Market. Washington DC , International Access Corporation (IAC); 2002.

25. Selifonova OV, Jessen H, Gort SJ, Selmer T, Buckel W: 3-Hydroxypropionic acid and other organic compounds. PCT WO 02/ 42418. 2002.

26. Ngheim NP, Donnelly MI, Millard CS, Stols L: Method for the production of dicarboxylic acids . 1999.

27. Reichstein T: Process for the manufacture of levoascorbic acid (vitamin C). US patent 2,265, I II. 194I.

28. Skory CD: Fungal lactate dehydrogenase gene and constructs for the expression thereof. US Patent 53538I . 2000.

29. Richard H, Foster JW: Escherichia coli glutamate- and argininedependent acid resistance systems increase internal $\mathrm{pH}$ and reverse transmembrane potential. Journal Of Bacteriology 2004, | 86( ( 8):6032-604|

30. Richard HT, Foster JW: Acid resistance in Escherichia coli. Advances In Applied Microbiology, Vol 52 2003, 52:167-186.

31. Poole RC, Halestrap AP: Transport Of Lactate And Other Monocarboxylates Across Mammalian Plasma-Membranes. American Journal Of Physiology 1993, 264(4):C76I-C782.

32. Walter A, Gutknecht J: Monocarboxylic Acid Permeation Through Lipid Bilayer-Membranes. Journal Of Membrane Biology 1984, 77(3):255-264.

33. Kirkpatrick C, Maurer LM, Oyelakin NE, Yoncheva YN, Maurer R, Slonczewski JL: Acetate and formate stress: Opposite responses in the proteome of Escherichia coli. Journal of Bacteriology 200I, I 83(2I):6466-6477.

34. Roe AJ, McLaggan D, Davidson I, O'Byrne C, Booth IR: Perturbation of anion balance during inhibition of growth of Escherichia coli by weak acids. Journal Of Bacteriology 1998, I 80(4):767-772.

35. Roe A], O'Byrne C, McLaggan D, Booth IR: Inhibition of Escherichia coli growth by acetic acid: a problem with methionine biosynthesis and homocysteine toxicity. Microbiology-Sgm 2002, I 48:22I5-2222

36. van Maris AJA, Konings WN, van Dijken JP, Pronk JT: Microbial export of lactic and 3-hydroxypropanoic acid: implications for industrial fermentation processes. Metabolic Engineering 2004, 6(4):245-255.

37. Narayanan N, Roychoudhury PK, Srivastava A: L (+)lactic acid fermentation and its product polymerization. Electronic Journal Of Biotechnology 2004, 7(2): 167-U2.

38. Saitoh S, Ishida N, Onishi T, Tokuhiro K, Nagamori E, Kitamoto K, Takahashi H: Genetically engineered wine yeast produces a high concentration of L-lactic acid of extremely high optical purity. Applied And Environmental Microbiology 2005, 7I(5):2789-2792.
39. Ikeda M, Nakagawa S: The Corynebacterium glutamicum genome: features and impacts on biotechnological processes. Applied Microbiology And Biotechnology 2003, 62(23):99-109.

40. Zeikus JG, Jain MK, Elankovan P: Biotechnology of succinic acid production and markets for derived industrial products. Applied Microbiology And Biotechnology 1999, 5 I (5):545-552.

41. Willke T, Vorlop KD: Biotechnological production of itaconic acid. Applied Microbiology And Biotechnology 200I, 56(3-4):289-295.

42. Nelson DL, Cox MM: Lehninger Principles of Biochemistry. 3rd edition. New York, NY, Worth Publisher; 2000.

43. Harrington CA, Rosenow C, Retief J: Monitoring gene expression using DNA microarrays. Current Opinion In Microbiology 2000, 3(3):285-291.

44. Goulbourne E, Matin M, Zychlinsky E, Matin A: Mechanism Of Delta-pH Maintenance In Active And Inactive Cells Of An Obligately Acidophilic Bacterium. Journal Of Bacteriology 1986, I 66(I):59-65.

45. Maurer LM, Yohannes E, Bondurant SS, Radmacher M, Slonczewski JL: pH regulates genes for flagellar motility, catabolism, and oxidative stress in Escherichia coli K-I2. Journal Of Bacteriology 2005, I87(I):304-319.

46. Choi SH, Baumler DJ, Kaspar CW: Contribution of dps to acid stress tolerance and oxidative stress tolerance in Escherichia coli OI57 : H7. Applied And Environmental Microbiology 2000, 66(9):39||-39|6.

47. Kroll RG, Booth IR: The Relationship Between Intracellular Ph, The Ph Gradient And Potassium-Transport In EscherichiaColi. Biochemical Journal 1983, 216(3):709-716.

48. McLaggan D, Naprstek J, Buurman ET, Epstein W: Interdependence Of $\mathrm{K}+$ And Glutamate Accumulation During Osmotic Adaptation Of Escherichia-Coli. Journal Of Biological Chemistry 1994, 269(3):1911-1917.

49. Sung HW, Chen CN, Chang Y, H.F. L: Biocompatibility Study of Biological Tissues Fixed by a Natural Compound (Reuterin) Produced by Lactobacillus Reuteri. Biomaterials 2002, 23:3203-32I4.

50. Ganzle MG: Reutericyclin: biological activity, mode of action, and potential applications. Applied Microbiology And Biotechnology 2004, 64(3):326-332

51. Luthi-Peng Q, Dileme FB, Puhan Z: Effect of glucose on glycerol bioconversion by Lactobacillus reuteri. Applied Microbiology And Biotechnology 2002, 59(2-3):289-296.

52. Rasch $M$ : The influence of temperature, salt and $\mathbf{p H}$ on the inhibitory effect of reuterin on Escherichia coli. International Journal of Food Microbiology 2002, 72:225-23I.

53. Goodson M, Rowbury RJ: Habituation to normally lethal acidity by prior growth of Escherichia coli at a sub-lethal acid pH value. Lett Appl Microbiol 1989, 8:77-79.

54. Lin JS, Smith MP, Chapin KC, Baik HS, Bennett GN, Foster JW: Mechanisms of acid resistance in enterohemorrhagic Escherichia coli. Applied And Environmental Microbiology 1996, 62(9):3094-3100.

55. Castanie-Cornet MP, Penfound TA, Smith D, Elliott JF, Foster JW: Control of acid resistance in Escherichia coli. Journal of Bacteriology 1999, I 8 I(I I):3525-3535.

56. Lin JS, Lee IS, Frey J, Slonczewski JL, Foster JW: Comparative-Analysis Of Extreme Acid Survival In Salmonella-Typhimurium, Shigella-Flexneri, And Escherichia-Coli. Journal Of Bacteriology 1995, I77(14):4097-4104.

57. Booth IR: The regulation of intracellular $\mathbf{p H}$ in bacteria. Novartis Found Symposium 1999, 22 I:19-37.

58. Storz G, Imlay JA: Oxidative Stress. Current Opinions in Microbiology 1999, 2:188-194.

59. Dien BS, Nichols NN, Bothast RJ: Recombinant Escherichia coli engineered for production of L-lactic acid from hexose and pentose sugars. Journal Of Industrial Microbiology \& Biotechnology 200I, 27(4):259-264.

60. Vemuri GN, Eiteman MA, Altman E: Effects of growth mode and pyruvate carboxylase on succinic acid production by metabolically engineered strains of Escherichia coli. Applied And Environmental Microbiology 2002, 68(4): I7I 5 - 1727.

6I. Chang DE, Jung HC, Rhee JS, Pan JG: Homofermentative production of D- or L-lactate in metabolically engineered Escherichia coli RRI. Applied And Environmental Microbiology I999, 65(4): 1384- 1389 
62. Gruber PR, Hall ES, Kolstad J], Iwen ML, Benson RD, Borchardt RL: Continuous process for manufacture of lactide polymers with controlled optical purity. US Patent 5142023. Cargill, Inc.; 1992.

63. Donnelly MI, Millard CS, Clark DP, Chen MJ, Rathke JW: A novel fermentation pathway in an Escherichia coli mutant producing succinic acid, acetic acid, and ethanol. Applied Biochemistry And Biotechnology 1998, 70-2:187-198.

64. Marz U: RGA-I03R Worldwide Markets for Fermentation Ingredients. .

65. Paster M, Pellegrino JL, Carole TM: Energetics Incorporated. In Industrial Bioproducts: Today and Tomorrow Washington DC , US Department of Energy, Office of Energy Efficiency and Renewable Energy \& Office of the Biomass Program; 2003.

Publish with Biomed Central and every scientist can read your work free of charge

"BioMed Central will be the most significant development for disseminating the results of biomedical research in our lifetime. "

Sir Paul Nurse, Cancer Research UK

Your research papers will be:

- available free of charge to the entire biomedical community

- peer reviewed and published immediately upon acceptance

- cited in PubMed and archived on PubMed Central

- yours - you keep the copyright 